\title{
Energy Efficiency in Historic Buildings: a Tool for Analysing the Compatibility, Integration and Reversibility of Renewable Energy Technologies
}

\author{
Elena Lucchi ${ }^{1}$,* \\ ${ }^{1}$ Politecnico di Milano, Milano, Italy \\ * Corresponding author. Tel: +39 0396085262, E-mail: elena.lucchi@polimi.it
}

\begin{abstract}
The paper presents a tool for defining the most appropriate energy and environmental retrofit on cultural heritage, to enhance the historical value of a building, to preserve the surrounding landscape, to reduce energy consumption and to improve human comfort, health and safety. It allowed the evaluation of the conservation risks, energy consumption, spatial layout and maintenance procedures and also led to a proposal on the most appropriate energy actions. The tool examines the synergies and difficulties of integrating green practices with historic preservation, and offers recommendations for ways in which sustainable standards could be more accommodating for historic and bounded buildings. The approach was used in the Renaissance building of Sant'Alessandro University located in the centre of Milan (Italy).
\end{abstract}

Keywords: Renewable energy, Cultural heritage, Compatibility, Integration, Reversibility

\section{Introduction}

The architectural heritage is a capital of irreplaceable spiritual, cultural, social and economic value. Old buildings help to understand the past and the concerns of the society that created them. The interplay between historic buildings, energy efficiency and sustainability is a topic of great importance. Environmental sustainable and energy savings measurements can be considered as a means of protecting real estate, not necessarily in contrast with conservation policies. There are numerous compelling reasons to believe that preservation concerns with environmentally sustainable development. Historic buildings are often located in densely populated urban areas, where infrastructure and mass transit already exists, thereby eliminating the need for new infrastructure and encouraging alternative models of transportation. Historic buildings are also typically constructed with durable and local materials, and are often sited for having full advantage of their surrounding environment. Furthermore, there is high embodied energy in ancient patrimony, which is defined as the sum of energy required to extract or harvest a raw material, manufacture and fabricate that material into a useful form, and transport it to the place of use. Heritage conservation is also a key component for economic revitalization of cities' centre. Often, historic buildings serve as small business incubators. Finally, to increase the preservation of cultural heritage is an important component of social sustainability.

\subsection{Energy efficiency policies}

Energy efficiency is a cen tral theme in the European policies. The Directive on energy performance (2002/91/EC) requires minimum energy standards for new and existing buildings that undergo major renovation. Despite the Directive admits a few exception for listed buildings, the International Energy Standards cannot be completely waived. Energy performance requirements can be excluded only "(...) where compliance with requirements would unacceptably alter their character or appearance" (Art. 43). At the same time, recent European policy officially introduces the concept of energy balance towards nearly zeroenergy buildings and incentives the decreasing of $20 \%$ of environmental emissions and the increasing of $20 \%$ of renewable energy technologies within 2020 (2010/31/EU Directive). To achieve these goals, it is necessary to reduce user demand as well as to improve the efficiency 
of energy systems and to use renewable sources. Heritage must adapt to changes, physical and intellectual, within its environment. The decision, inevitably, must be faced with the energy efficiency of existent buildings, independently by local bounds. Therefore we should develop techniques to maintain, refurbish and adapt the existing buildings to new requirements.

\subsection{Environmental sustainability policies}

Preservation-based sustainability is offered as a $\mathrm{m}$ ore comprehensive approach to development, as it takes into consideration environmental, economic, social, and cultural implications of buildings. These principles constitute the basis of the more important sustainable tools (1). These programs emphasize design, construction and operation for obtaining a "high green performance" building to reduce environmental impacts through energy efficiency, use of recycled materials, storm water management, and other innovations.

\subsection{Sustainable conservation principles}

High energy and environmental performances may lead the preservation of a building, but each action on historic and listed heritage gives attention to the matter of vulnerability, physical alteration, and decreasing of immaterial and material value. The most important principles for sustainable conservation regard:

- Compatibility: modern materials tend to be harder, less flexible, and less moisture permeable than traditional ones. For these reasons when are used in direct conjunction with historic fabric can greatly accelerate decay in the original work;

- Aesthetic integration: history and authenticity of historic building should be respected as essential to its significance;

- Reversibility: the unavoidable changes of the building should wherever possible be made to be fully reversible. Adopting this principle, the valuable historic fabric can be returned to its original state without damaging the building;

- Emphasis on effective maintenance: care, planned conservation, and management should include regular inspections so that defects can be discovered whilst still small and easily fixable. This permits to preserve historic fabric, minimize cost and disruption to the building's owners and users.

The retention of older buildings or the re-using of components in-situ and allowing for their energy upgrading in benign and sympathetic ways, can provide excellent finished results which are fully in accordance with the principles of building conservation and sustainability.

\section{Methodology}

Energy efficiency and environmental sustainable programs should be developed on the basis of a thorough knowledge of the property, blending technological and landscape requirements. This means understanding original construction, alterations, actual conditions, qualities, material and immaterial values, lacks, and retrofitting opportunities. The tool is structured in the following phases:

- Historical analysis of city, urban site and heritage building;

- Analysis of functions, performance and needs of users;

- Building energy audit;

- Evaluation of environmental performance;

- Individualization of energy and environmental lacks;

- Definition of possible retrofitting actions;

- Evaluation of the compatibility, the integration and the reversibility of each action.

1) See: U.S. Green Building Council's "Leadership in Energy and Environmental Design" (LEED), "Building Research Establishment Environmental Assessment Method" (BREAM), "Comprehensive Assessment System for Building Environmental Efficiency" (CASBEE), Green Star, Minergie and Ecolabe programs. 
The tool allowed the evaluation of the conservation risks, energy consumption, spatial layout and maintenance procedures and led to propose the most appropriate actions (Fig. 1).

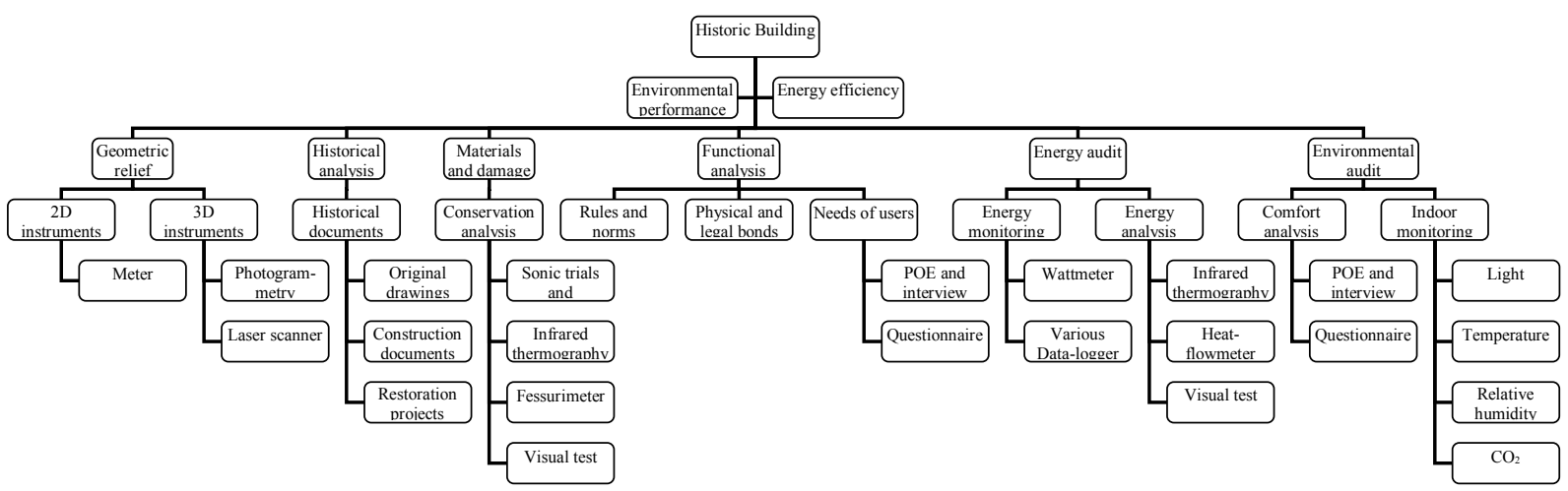

Fig. 1. Method for analyzing energy and environmental performance of historic building.

\section{The case study: Sant'Alessandro University in Milan}

The tool was used in the Renaissance building of Sant'Alessandro University located in the centre of Milan (Italy). The construction has been modified during the centuries. The most important projects regard the addition of a Baroque Church and the transformation into a Public University in $\mathrm{XX}^{\mathrm{TH}}$ Century.

\subsection{Historical analysis}

Technical compatibility and aesthetical integrations are guarantee only by a deep knowledge of history, dimensions, structures, original and restoration materials, and management procedures. Also, it is important to comprehend how modern materials and technical approaches impact on ancient buildings. Failure to understand the nature of the building being inspected can have serious technical consequences, physical damage and possible legal claims. The historical analysis comprehend the physical relief, the study of traditional construction and local techniques, the instrumental tests of original and restoration materials. Cartographic map, land registry, cadastral map, historical and construction drawings permit to reconstruct the original form, the spatial relation and the history of the building. First of all, the original drawings, the construction documents and the restoration projects were collected. The geometric relief was made to verify dimensions, performances, and damage of structures. It was conducted using linear meter, photogrammetry and laser scanner, in order to reconstruct the morphology, the form, the dimensions, the spatial layout, the external and internal features. Final result after processing of the raw data produced drawings, CAD models, 3D surface models and video animations. Particularly, the analyses permitted to verify the reliability of historical documentation and to comprehend the constructive phases and the modifications realized in different ages.

\subsection{Performance and functional analysis}

First of all, it is important to define the meaning of "high performances" in historic building through the right balance with requirements, rules, norms, physical and legal bonds that condition the quality of life for occupancies. The international literature (ASHRAE, English Heritage) proposes to provide specific "classes of performance" for satisfying needs of access, comfort and security. For this purpose, all activities made by the users (students, teachers, staff, stakeholders) were investigated during different hours and periods of the year. In this way, a specific knowledge of the real requests was obtained. 


\subsection{Energy audit}

Building audit is a process to evaluate the energy consumption of the building in order to identify the opportunities for retrofit actions (2). This means to effect inspection, analysis and survey of energy flow, for reducing energy inputs, improving comfort, health and safety. Energy performance of envelope, functioning of mechanical systems, and management data are necessary to realize the audit. Particularly, the following data was obtained:

- Location, urban planning, orientation and environmental context;

- Dimensions of the buildings;

- Construction features of building envelope;

- Efficiency, functioning and maintenance of mechanical and electric systems;

- Leakage rate or infiltration of air;

- Energy consumption.

\subsection{Evaluation of environmental performance}

Environmental evaluation considers the opposite exigencies for caring and valorizing the cultural heritage. The balance for conservation and human comfort was defined through the confront among environmental, caretaker and management standards. The evaluation regarded the following analyses:

- Microclimate monitoring of light (illumination level, luminance, UV and IR radiance), temperature (external and internal temperature, daily and seasonal gradient), relative humidity (external and internal relative humidity, daily and seasonal gradient) and air (air change rate, indoor air movement, $\mathrm{CO}_{2}$ concentration, and pollutants dissemination);

- Thermal, visual and acoustic comfort of users;

- Maintenance procedures and operating data (opening times, operation hours, number and frequency of the visitors).

\section{Results: energy and environmental performance}

In Sant'Alessandro University was particularly difficult to find information about the technological characteristics because of the lack of original plans and of the alterations of the original asset. In order to individualize the original structure, destructive testing, such as coring or endoscope techniques, were excluded because the methods are not suitable for the architectonic values of the building. For this reason, technological data were estimated comparing handbooks, regulations, heat flowmeter measurements, infrared thermography and computations of energy performances.

\subsection{Evaluation of energy performance}

Non-destructive testing gave a p recise recognition of constructive phases, authentic parts, original and restoration materials, constructive techniques, decay, durability and resistance of the structure. Particularly, infrared thermography verified the historical data and individualized the most important energy problems. IR inspection evidenced the presence of thermal bridges, low U-value of envelope, heat gradient through the walls, internal moisture, mould and air leakage at windows, joints and junctions of the building envelope. Sonic trial proved the presence of some mechanical anomalies and confirmed the real composition of the envelope realized by double masonry in bricks and rubble mix. Heat flowmeter measurement calculated the thermal conductance of the walls (Fig. 2).

\footnotetext{
2) The European Directive 2006/32/CE related to energy efficiency in final users defines energy audit as a «[...] systematic procedure to obtain adequate knowledge of the energy consumption profile of a building or group of buildings, an activity and/or industrial facility or public or private services, to identify and quantify energy saving opportunities from a cost-effectiveness profile and to report the results».
} 

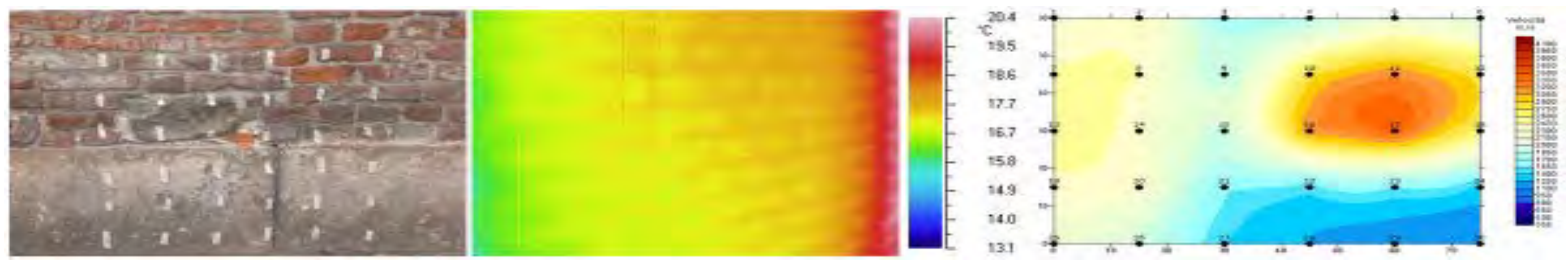

Fig. 2. Confront among visual test, infrared thermography and sonic trial of opaque envelope.

On plants, infrared thermography showed the high temperature of radiators $\left(80^{\circ} \mathrm{C}\right)$ and of artificial lighting $\left(60^{\circ} \mathrm{C}\right)$ and the functioning of plant in unused ambient. Visual test and environmental monitoring illustrated the low energy performance of HVAC, the incorrect energy management relating to the continual opening of windows and doors, the internal high temperature of air and ignition of lighting during all the day (Fig. 3).
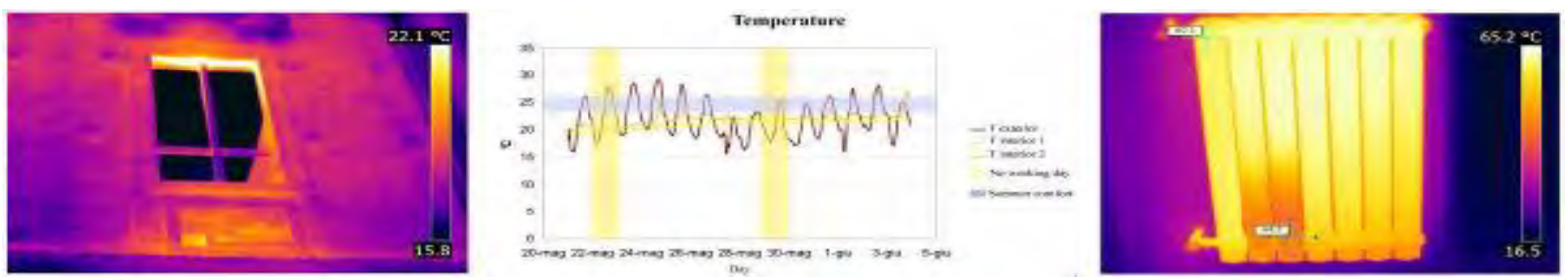

Fig. 3. Environmental monitoring and infrared thermography showed the high temperature of air.

Energy monitoring confirmed the low performance of HVAC and the high fuel bills of the last five years. Energy opportunities of the building regard the thermal mass of envelope, the breathable, and the natural moisture management. Energy performances were evaluated using static and dynamic simulations. The building was in the lower class of energy label with high annual energy consumption.

\subsection{Evaluation of environmental performance}

Environmental tests verified the presence of damage due to great flux of people and of incompatibility of the protecting policies. Users comfort was appraised with questionnaires and interviews conducted using the Post Occupancy Evaluation method. The analyses were realized on three categories of users: students, teachers and staff. The comparison between discomfort problems and environmental conditions showed the malfunctioning of mechanical systems and the use of incorrect management procedures. Particularly, environmental treats regarded high temperature and heat gain in the attics (mean temperature: $24^{\circ} \mathrm{C}$ in winter and $33^{\circ} \mathrm{C}$ in summer), high value of relative humidity in the laid undergrounds (60-65\%), temperature fluctuation, low light level (200-300lux), discomfort glare and inadequate lighting (Fig. 4).
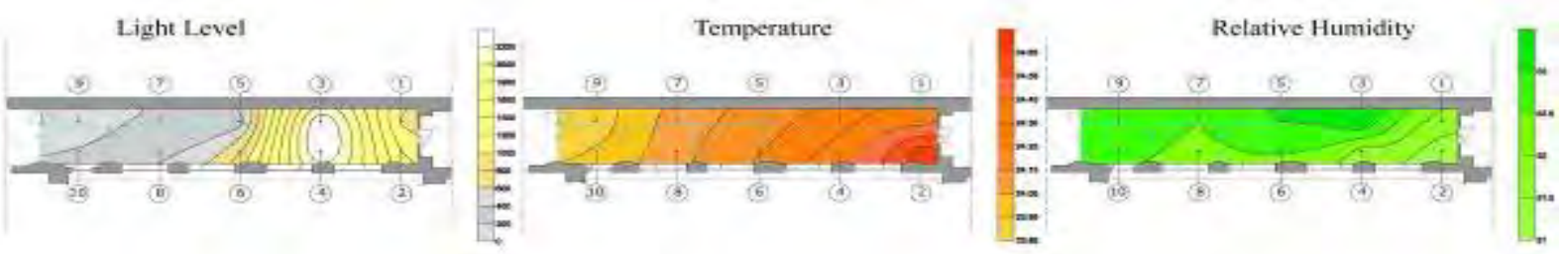

Fig. 4. Monitoring of light level, temperature and relative humidity of air in a room.

Comfort analysis demonstrated the abuse of artificial lighting and the use of wrong light sources (neon light). There is a direct relationship between environmental condition and surface decay. Damage regards cracks, surface breaking, moisture sources, water absorption, and percolation (Fig. 5). 


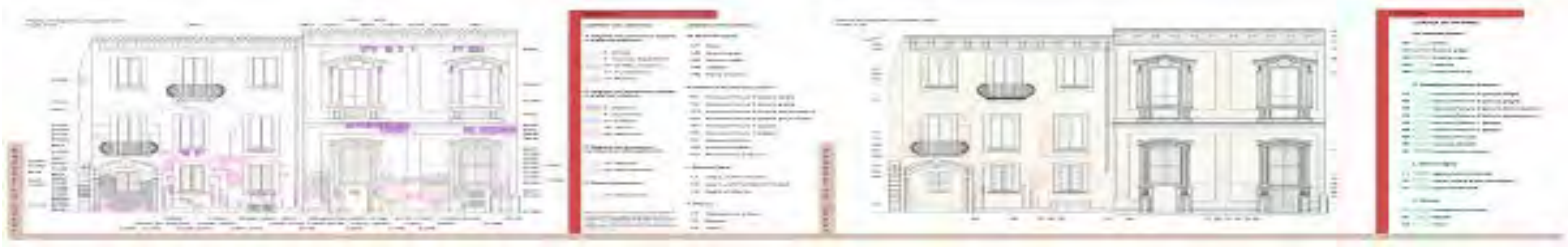

Fig. 5. Decay problems are directly related to environmental condition and regard cracks, surface breaking, moisture sources, water absorption, and percolation.

\section{Retrofit actions}

The integration of conservation, design and operation is a radical approach to future-proofing historic buildings. Compatibility, integration and reversibility of retrofit actions are the principal items involved in the study of historic buildings. The lack of compatibility may cause serious long term problems of decay, such as bacteriological germination due to air permeability of windows or cracking in masonry due to low mechanical performance, water absorption, percolation and internal moisture. The lack of integration could have a negative effect on the physical composition and static resistance of the structure.

First of all, in Sant'Alessandro University was necessary to understand how traditional buildings behave as environmental systems. Non-destructive testing shows that the envelope didn't require insulation systems because the walls guarantee good thermal and hygrometric performances, both in winter and in summer. However, the invasiveness of internal or External Thermal Insulation Composite Systems (ETICS) or double façades may erase the historical traces and artistic value of the heritage. On the laid undergrounds it is possible to insulate with thermal plaster or internal rigid insulation in transpiring materials, because of the absence of historic traces. The basement and the roof have high energy losses due to the missing of insulation. To insulate the lower insole preserving the original floor, it is possible to add rigid or sprayed foam insulation on the internal surface. To insulate the roof could be installed underside insulation or insulated ceiling characterized by mechanical, chemical and physical compatibility with the original roof. Transparent envelope has high thermal losses and air infiltrations. For this reason, it is necessary to evaluate the replacement of existent glasses and frames with new windows (low-e glasses and wooden frames) having better performances of thermal insulation, air permeability, water resistance and UV protection. The PVC cover on the roof presents convection, air leakage, water adsorption and solar gain. It is necessary to study the replacement with Transparent Insulating Materials, solar control or selective glasses. For protecting the office from solar gain and discomfort glare can be installed internal shading devices and curtain (Table 1).

The main problem is caused by mechanical plants. The existent boilers have very low thermal performance. May be evaluated the replacement with an innovative heat pump, that balances heating and cooling needs. The low performance of radiators and fan-coil get worse by the absence of insulation on thermal distribution, climatic control and heat accounting systems. Furthermore, air-conditioning systems damages the artifacts and the buildings because the movement of air masses soils and dusts the walls, the frescoes, the inlays and the decorations. The intervention requires the evaluation of the insertion of radiant panels on existing floor (not characterized by particular historic value). Instead, it is necessary to insert thermostatic valves on existing radiators and heat accounting systems. The electric system not always is safety from risks. The lighting has discrete energy performances, guaranteed by the integration with daylight, halogen lamps and periodic maintenance on inefficient devices. To increase the level of light can be installed diffusers on existent glasses of the office and high efficiency sources. Solar energy technologies must be integrated within buildings and their 
surrounding landscapes, in order to obtain financial support and to increase their efficiency. The use of photovoltaic panels is recommended for decreasing the high electric consumption (Table 2).

Table 1. Definition of possible retrofit actions for the building envelope.

\begin{tabular}{|c|c|c|c|}
\hline Measurements & Compatibility & Integration & Reversibility \\
\hline \multicolumn{4}{|c|}{ Roofs } \\
\hline Add rigid insulation on the top surface & घ & m & घ \\
\hline Apply sprayed foam insulation to the top & घ & $\mathbf{m}$ & - \\
\hline Install underside insulation & घ & - & घ \\
\hline Install insulated ceiling & a & - & - \\
\hline \multicolumn{4}{|c|}{ Walls } \\
\hline Insulate with thermal plaster or wall & - & - & - \\
\hline \multicolumn{4}{|l|}{ 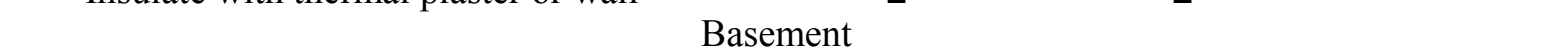 } \\
\hline \multicolumn{4}{|c|}{ Windows and doors } \\
\hline Install high-efficiency doors and windows & घ & - & - \\
\hline Install low-e glasses on existing frames & - & घ! & - \\
\hline Transparent Insulating Materials & - & - & - \\
\hline Install selective materials & - & घ & - \\
\hline Install weather-stripping on windows & ! & $\mathbf{\square}$ & $\mathbf{\square}$ \\
\hline \multicolumn{4}{|c|}{ Shading devices } \\
\hline \multicolumn{4}{|c|}{ Day lighting systems } \\
\hline $\begin{array}{l}\text { Install diffusers on existent glasses } \\
\text { Install interior curtain }\end{array}$ & a & a & \\
\hline \multicolumn{4}{|c|}{$\begin{array}{l}\text { Incompatible actions: replace with insulated or green roof; insert ETICS or double façades; install } \\
\text { storm windows, films or supplemental glazing; add veranda or solar greenhouse; maintain fit, } \\
\text { closure and sealing of windows; install external shading devices, skylights, light pipes or light } \\
\text { shelves; painting for minimizing the sunlight absorption } \\
\text { Note: a = Yes - = No - = Specific project is required }\end{array}$} \\
\hline
\end{tabular}

Table 2. Definition of possible retrofitting actions for plants and renewable technologies.

\begin{tabular}{l}
\hline Measurements Compatibility \\
Test boiler efficiency \\
Optimize the air-fuel ratio
\end{tabular}

Incompatible actions: install mechanical ventilation pant; insulate the distribution system; insert wind technology systems

Note: $\square=$ Yes $\quad-=$ No $\quad=$ Specific project is required 
A software simulation with Design Builder allowed to verify the energy benefit related to various retrofit actions. In this way, the proper interventions have been selected in order to improve energy and environmental efficiency of the building (Table 3 ).

Table 3. Retrofitting actions to be realized in Sant'Alessandro University .

\begin{tabular}{|c|c|c|c|c|c|}
\hline & & Measurements & & Reduce 0 & \\
\hline & & & $\begin{array}{l}\text { Thermal } \\
\text { loss }\end{array}$ & $\begin{array}{l}\text { Thermal } \\
\text { gain }\end{array}$ & $\begin{array}{c}\text { Air } \\
\text { infiltrations }\end{array}$ \\
\hline$\Lambda$ & Roofs & Add insulation on the top surface & $70-80 \%$ & - & - \\
\hline $\mathrm{A}$ & & Install insulated ceiling & $60-70 \%$ & - & - \\
\hline & Walls & Insulate with thermal plaster & $30 \%$ & - & - \\
\hline B & & Insulate with thermal wall & $50 \%$ & - & - \\
\hline $\mathrm{C}$ & Basement & Install underside insulation & $50-60 \%$ & - & - \\
\hline $\mathrm{D}$ & Doors & Install high-efficiency & $10-20 \%$ & - & $70 \%$ \\
\hline & & Install high-efficiency windows & $50-70 \%$ & $25-40 \%$ & $90 \%$ \\
\hline E & Windows & Install low-e glasses on frames & $30-40 \%$ & $25-40 \%$ & $60 \%$ \\
\hline & & Install weather-stripping & - & - & $40 \%$ \\
\hline & & Transparent Insulating Materials & $50-80 \%$ & $30-40 \%$ & $50 \%$ \\
\hline $\mathrm{F}$ & Curtain Roof & Install selective materials & $50-60 \%$ & $50-60 \%$ & $50 \%$ \\
\hline & & Install internal shading devices & - & $20-30 \%$ & - \\
\hline G & Boiler plants & $\begin{array}{l}\text { Test boiler efficiency } \\
\text { Optimize the air-fuel ratio }\end{array}$ & $20 \%$ & $\begin{array}{l}- \\
-\end{array}$ & - \\
\hline $\mathrm{H}$ & & Install thermostatic controls & $30 \%$ & - & - \\
\hline I & Electric & Install the most efficient lamps & $30 \%$ & - & - \\
\hline $\mathrm{L}$ & systems & Maintenance & - & - & - \\
\hline Note: & $=$ Most eff & ency action & & & \\
\hline
\end{tabular}

The most important problem regards the education of staff and stakeholder to a correct thermal and light management of rooms, corridors and foyers. The building can save up to $35 \%$ energy, without compromising heritage value and occupancies comfort, by implementing the mentioned ECMs.

\section{Conclusion}

The objective of energy end environmental quality in historic building can only be achieved by combining a diversification of energy production from various renewable sources together with cutting greenhouse gas emissions. The goal may be obtained only by an integrate analysis of historic, dimensional, functional, energy and environmental matter. A deep knowledge of a real need permits to propose the most appropriate retrofit actions. On the contrary, non-critical application of energy standards and general models disadvantage the existing building or its parts, without getting a real advantage in the overall energy balance.

\section{References}

[1] American Society of Heating, Refrigerating and Air Conditioning Engineers, ASHRAE Handbook. Fundamentals, ASHRAE, Atlanta, 2009.

[2] English Heritage, Energy Conservation in Traditional Buildings, English Hertitage, London, 2008.

[3] E. Lucchi, Tutela e v alorizzazione. Diagnosi energetica e ambientale del patrimonio culturale, Maggioli Editore, Sant'Arcangelo di Romagna, $1^{\text {st }}$ Edition 2009.

[4] A. Thumann, W. J. Younger, Handbook of Energy Audits, The Fairmont Press, Lilburn, $7^{\text {th }}$ Edition, 2008. 